\title{
On the search for environmental sustainability in Africa: the role of governance
}

\author{
Ibrahim Ayoade Adekunle ${ }^{1,2}$ (I)
}

Received: 1 April 2020 / Accepted: 26 October 2020 / Published online: 20 November 2020

(C) Springer-Verlag GmbH Germany, part of Springer Nature 2020

\begin{abstract}
Africa remains the most affected by environmental degradation, thereby exacerbating the negative effect of climate change in the region. Little empirical credence has been leaned to the institution-environmental sustainability relationship in Africa. This omission in the literature of environmental sustainability is abysmal, considering the role of institutions and government in ecological preservation. To inform policy and research on the subject matter, we estimated a unbalanced panel data of the indices of good governance and strong institutions to explain transformation to environmental sustainability using the dynamic system generalised method of moment estimator from 1996 through 2017. Findings suggested a positive relationship between the rule of law and regulatory quality and transformation to environmental sustainability. An inverse relationship between government effectiveness and environmental sustainability was established. We recommended concerted effort at an institutional level such that policy and punishment for violation of greenhouse strategies will be optimum.
\end{abstract}

Keywords Institutions $\cdot$ Governance $\cdot$ Environmental sustainability $\cdot$ System GMM $\cdot$ Africa

JEL classification $\mathrm{E} 62 \cdot \mathrm{G} 13$

\section{Introduction}

The literature on environmental sustainability has grown tremendously, but with little or no experimental proof to show the dominant influence that institutions and governance play in the quest for environmental sustainability in Africa, thus leaving out essential elements that could trigger a paradigm shift from the convention environmental sustainability pursuit management in Africa. It is, therefore, necessary to identify the quantitative impact of institutions and governance on environmental management as well as innovative and practical pathways that can address the seemingly inexorable trends in global environmental change in Africa (Ahenkan and OseiKojo 2014). Africa environment has been changing for years,

\footnotetext{
Responsible Editor: Philippe Garrigues

Ibrahim Ayoade Adekunle

adekunle_ia@yahoo.com

1 Department of Economics, Olabisi Onabanjo University, Ago-Iwoye, Ogun State, Nigeria

2 European Xtramile Centre of African Studies, Liège, Belgium
}

but the broader concerns of public health deterioration remain unresolved. In Africa, challenges of environmental pollution, rising population growth, and inaccessibility to clean water are some of the impediments recorded in the public health discourse (Hsieh and Shannon 2005). From the problems of gas flaring in the Niger Delta in Nigeria to malnutrition in Somalia and oil spillage in Angola, the Africa environmental degradation cases go on and on causing nearly one out of four deaths in the region (World Health Organization 2014). Since the development of Africa nations has been linked to industrialisation, the growth trajectory of carbon emission has doubled at the least (Jolley and Douglas 2014). While Africa's search for inclusive growth and poverty eradication continues, little attention has been paid to the consequences of these environments degrading growth strategies.

It should be noted that public health ranks most prominent among our priorities as human. As such, our consumption pattern in terms of intake and inhalation plays a significant role in our overall well-being (Prilleltensky 2012). The stake for a paradigm shift to pollution abatement strategies to growth in Africa cannot be higher if we are conscious about realising the Africa 2063 Agenda. At a time when the world is panicking due to death recorded from COVID-19 and other 
associated disease outbreaks, Africa relatively less affected is not ready for the consequences of an environment that is continuously degraded. The herbal solution made primarily from the forest is the conventional source of medics for rural Africa. When massive deforestation is encouraged to aid urbanisation, the fortress that Africans relied on for a long time will become illusionary in the face of impending crisis.

There is no gainsaying that Africa nations have limited institutional and technical capacities to tackle sustainability and environmental, ethical issues (Adekunle et al. 2020; Gu et al. 2018). In recent times, it is becoming apparent that the age-long influence of colonisation, globalisation, and urbanisation negatively impinged on the African environmental ethics, indigenous and local knowledge systems. The eras of state colonialism, post-independence growth trajectories, urbanisation, and globalisation have redefined the accessibility and usage of natural resources in Africa (Jolley and Douglas 2014). The Africa environmental sustainability challenges are not unconnected to collapsed and faded indigenous and local knowledge system (Balmford et al. 2001). Before the introduction of forest mining in Africa, the forest has been a cohort that epitomises power, origin, wealth, sacredness, and security to the African people (Shackleton et al. 2007). The adoption of democratic dispensation in most African countries against the conventional monarchical system of governance was an apparent beginning of to the paradigm shift in natural resource accessibility and usage which have a clear footprint on the environmental degradation manifestations in Africa (Cobbinah et al. 2015). Thus, the type of governance structure and institutional framework in a nation, in turn, becomes the most pervasive factor that determines the depth of environmental quality or degradation that a country can experience (Adekunle et al. 2020; Hsieh and Shannon 2005). Democratic dispensation, natural resource management options, interactions of states with social actors, quality of laws, and enforcement strategies in place to safeguard the environment are essential elements of institutions and governance for the realisation of desirable environmental sustainability objectives (McConnell 1997). Since governance at most general level involves collective bargaining for societal gains, there is an urgent need for the state environmental management objectives to be socially just and ecologically equitable. With the goals of African 2063 Agenda (the Africa we want) in sight, leaning empirical credence for inch-perfect policy formulation becomes apt and imperative.

The role of strong institutions in ensuring environmental quality extends to the public sector growth in terms of basic amenities including housing, efficient road networks, functional healthcare facilities, and more (Easterly and Levine 1997; Mbhalati 2014). The rising number of middle-class Africans, which has recently exceeded 300 million, is often associated with anti-environmental sustainability consumerism (Deep and Saklani 2014). Higher income is associated with higher demands (McConnell 1997). In a mixed economic system, as evident in most African nations, the role of governance in coordinating basic amenities in a manner that does not deface the environment is crucial (Ostrom 2008). Some African countries like South Africa, Egypt, and recently Rwanda made a giant stride in resolving environmental issues borne out of the housing deficiencies of their resident; however, majority of other African nation still experiences significant mismatch in the housing provision which has dire ecological implications (Cobbinah et al. 2015). It is not entirely out of place to say urbanisation in Africa is enmeshed in flawed logic and failures to comply with decarbonisation strategies amidst rising income of the region will result into equivalence loss in the environment which will eventually match their previously accrued gains from industrialisation. Recently, African urban centres have witnessed significant expansion that threatens their environment (Frumkin 2002). In major cities across Africa, idle and undeveloped lands are becoming scarce. With the growing number of buildings that forms the pillar of urbanisation and globalisation of major cities across Africa, the natural cycles of rainwater are disrupted since concrete lidding of floors interrupts them from soaking into the grounds (Friedl and Wüest 2002), thus making the African natural environment to take a hit. Increased houses across Africa would lead to higher environmental pollution because their usage is connected to the rising growth trajectory of carbon emission. In resolving the ambiguity of urban sprawl, Africa government ordinances towards environmental degradation are essential and need to be studied. It becomes apt to appropriate data and methodology to be able to lean empirical credence to the institution-environmental sustainability discourse to inform policy direction and research on the subject matter.

For low carbon emission strategies and a safe Africa, African government needs to explore innovative environmental problem-solving strategies (Hewitt 2013). Since governments are at the helm of affairs, they can pass laws to protect public health and create regulations to enforce them. The essence of governance is to protect its citizens and to preserve the environment and attendant resources from ecological footprints and hazardous wastes. The quantitative effects of this government environmental ordinances remain a prior unclear and need to be studied. The ecological economics literature in Africa focused on scrutinising the role of industries and businesses with regard to global and local ecosystems (see Barasa et al. 2017; Bradlow et al. 2011; Kumssa and Mbeche 2004; Mazzucato and Niemeijer 2002; Walker 1999, for examples). Technological improvement in the region has apparently shown the footprints of big polluters, but little is known about how the government aids or abates environmental degradation in Africa with respect to their institutional capacities. It is not even entirely clear whether the government engage big polluters in litigation processes and what does the quality of 
existing laws and orders, public sector strength in terms of government effectiveness, and the quality of regulations means for environmental sustainability in Africa. Without these empirical credence, it remains extremely difficult to establish evidence-based patterns of individuals' and households' unsustainable consumption, behaviours, and commitments to sustainability in Africa. Foley et al. (2011) argued that for environmental solutions to be effective, there is a need to embellish them in moral characters. At the helm of discouraging a national practice of environmental degradation are the government laws and enforcement strategies, particularly when it comes to asking the public to recycle materials, reduce travel, or switch off lights. Estimating the quantitative influence of institutions and governance for transformation to environmental sustainability is essential in policy formulation and development objectives towards the moral reforms.

Building on and extending the strong institutions and good governance for environmental sustainability framework in Africa, the current study, therefore, seeks to offer empirical credence on the roles of institutions and governance as a veritable means for environmental sustainability. The analysis assumes that individuals are at the core of transformation to sustainability, and hence, the government should provide an enabling environment for environmental sustainability to thrive. Our specific research question asks: what are the roles of institutions and governance in attaining environmental sustainability in Africa? What do governance and institutions mean in the context of natural resource management in Africa? What are the policy implications of institution-environmental sustainability management that address the food security concerns of the poor in ways that are socially just and ecologically viable? This study builds upon similar studies (although very few) in Africa (see Barasa et al. 2017; Sowman and Wynberg 2014; Walker 1999, for some examples) and many more across African borders (see Berman et al. 2012; Epstein et al. 2015; Hewitt 2013; Lehtonen 2004; Ostrom 2008, for other examples). This study extends the previous research by offering evidence-based empirical credence to governance and institutional dimensions that predict variations in natural resource management in African countries with dire ecological needs. This study aims to advance knowledge on the governance and institutional bottlenecks that have long impeded the realisation of environmental sustainability in Africa.

The empirical result informs policy formulation on the approaches to achieve optimal growth path without harming the environment. We tackle research questions raised by estimating a balanced panel data of indices of institutions and governance as a predictor of environmental sustainability in Africa using the dynamic system generalised method of moment (GMM). The dynamic system GMM estimator accounts for strict orthogonal violation present in the ordinarily fixed effect panel data estimation and neutralises the problems of endogeneity. Ecological footprints in African nations experiment at varying degrees. It is essential to employ a methodology well known for handling biases emanating from unobserved heterogeneity (Arellano and Bover 1995; Blundell and Bond 2000). Our focus is on African countries that experience dire ecological problems. In exploring the potentials of institutions and governance and in addressing the sustainability crisis, this study estimated panel data from 1996 to 2017 with a view of coming up with findings that can offer a credible panacea for environmental sustainability challenges. This paper comprises five intertwined sections - the introduction, literature review, methodology, results, and conclusion. The introductory part of the paper presents the rationale and urgency for institutions and governance in the transformation to environmental sustainability. The literature review appraised past studies and their contributions with apparent issues unresolved. The methodology section highlights the estimation strategy and data sources, and then the results section leans empirical credence to the role of institutions and governance for addressing environmental sustainability in Africa. The paper's discussion and conclusion underline the imperative for institutions and governance as an alternative for enhancing transformation to environmental sustainability.

\section{Literature review}

The literature on environmental sustainability has grown tremendously (outside the borders of Africa), but little attention has been paid to examine African environmental sustainability as induced by the institutional framework. In Africa, Bokpin (2017) appraise the moderating roles of governance and institutions in the FDI-environmental sustainability nexus from 1990 through 2013. The author found that FDI to impact environmental sustainability negatively, but the existing governance and institutional structures cushioned the adverse effect. A clear drawback on these findings is that they relied on fixed and random effect estimation procedure to estimate a short-term panel for 14 years in all African countries. The fixed and random effect has been established to run into problems of the degree of freedom when the numbers of observation in the panel are relatively short (see Henderson et al. 2008; Murtazashvili and Wooldridge 2008; Su and Yang 2015, for an extensive review).

Sowman and Wynberg (2014) in their grand findings on governance for justice and environmental sustainability in sub-Saharan Africa natural resource sector argued that institutional bottlenecks are the greatest obstacle to the attainment of environmental sustainability in SSA. They posit that the government makes and enforces laws that aid or abate the 
sustainable use of environmental resources and, more importantly, determine the optimal development path for growth and development with the sustainability of the environment insight. In other findings of Asongu and Odhiambo (2020), the authors assessed governance for environmental sustainability in sub-Saharan Africa. They found that political governance is positively related to carbon emissions, and institutional governance is negatively related to carbon emissions. Ben Youssef et al. (2018) assessed the innovative and institutional solutions for entrepreneurship and sustainability in Africa. In their analysis of environmental sustainability along the dimensions of entrepreneurship, they found that rising formal and informal entrepreneurship negatively influence environmental sustainability in 17 African countries. However, Turner (1999), in his analysis of conflict, environmental change, and social institution in Africa, found local knowledge and governance system to respond proactively to environmental change.

The author argues that local autonomy is better placed compared to the macroinstitutional arrangement since they have adequate knowledge of the immediate community and thus respond better to a deteriorating environment, land tenure systems, and many more in the Sahel region. Bhattarai and Hammig (2001) in their cross-country study of Latin America, Asia, and Africa found the prevailing institutional structure and dominant macroeconomic policies to influence tropical deforestation process. In other related findings on the environmental sustainability and institutional relationship in Africa, Asongu et al. (2018a) examined the role of ICT for environmental sustainability in Africa from 2000 through 2012. Using the generalised method of moment estimation procedure, the authors found ICT does not induce environmental degradation. In other findings of Asongu et al. (2018a) using interactive regressions, phone penetration negatively relates to environmental degradation.

Beyond African borders, institution-environmental sustainability has taken many dimensions. Lehtonen (2004) examines the environmental and social interface relationship in OECD countries. The author argued varying structural compositions of nations in the OECD are the primary determinant of the eventual threshold for environmental sustainability management for which institutions mediate. Berman et al. (2012) examine the roles of institutions in the transformation of coping capacity to adaptive capacity in the climate change adaptation process. The author argued that governance structures in place to handle adaptation challenges are essential in gauging the uncertainty that may arise from undesired anticipated and unanticipated climate change. Epstein et al. (2015) examined the institutional fit and the sustainability of social-ecological systems. The authors argued that countries around the world based their assessment of institutions and environmental sustainability nexus on ecological fit, social fit, and the socio-ecological system fits. The dimensions to the institution fit assessment depend on the problems the institutions are meant to address in the environmental sustainability management and the context to which the institutions operate.

Despite varying dimensions to which the environment sustainability management has been pursued in the literature, few studies in Africa have provided empirical credence on the subject matter. It shows that most policy formation on the environmental sustainability discourse in Africa are being conceived on mere theoretical disposition with no apparent evidence-based study a priori conducted. It is not surprising that Africa struggles to implement green growth initiatives in line with its counterparts in developed worlds. This study seeks to lean empirical credence to the underlying structural relationship between institutions and environmental sustainability in Africa with a view of coming up with findings that can redefine policy and research on the subject matter.

\section{Materials and methods}

\section{Model}

In gauging the environmental sustainability response to institutional factors in Africa, this study is a prototype of Swallow and Meinzen-dick (2009). The empirical strategy is to estimate a series of baseline fixed effect estimators by assuming that all explanatory variables are strictly exogenous. Second, we estimate a dynamic panel system generalised method of moment (GMM) estimators and impose (and test) the common factor restrictions to account for the potential endogeneity of regressors in a manner that is synonymous to leading GMM studies using African data (see Asongu et al. 2017; Asongu and Acha-Anyi 2019; Tchamyou 2019). The functional relationship is the following:

$E N V S U S_{i t}=f\left(I N S T_{i t}\right)$

where $i, t$ refers to country $i$ in period $t, E N V S U S_{i t}$ is environmental sustainability in country $i$ over period $t, t$ is the time series indices of the scope that the study intends to cover (1996 through 2018, (23 years), and $i$ is the domain that contains the cross-sectional characteristics of the data (53 African countries under investigation).

If the assumption of strict exogeneity on institutions and environmental sustainability is violated, our baseline fixed effect estimator is potentially inconsistent. Therefore, to obtain asymptotically consistent parameter estimates, we estimate single equation dynamic GMM estimators by using a common factor representation (Blundell and Bond 2000) 
The dynamic panel regression model to capture the relationship between institutions and environmental sustainability is specified as follows:

$$
\begin{aligned}
N R D_{i t} & =\rho+\omega N R D_{i t-1}+\theta I N S T_{i t}+\sum_{j=1}^{k} \delta_{j} X_{j_{i t}}+\gamma_{i}+\epsilon_{i}+\mu_{i t} j \\
& =1 \ldots \ldots ., k, i=1 \ldots \ldots \ldots, t=1 \ldots \ldots \ldots \ldots .
\end{aligned}
$$

where $N R D_{i t}$ gives the depth of natural resource depletion as a proxy for environmental sustainability of country $i$ over period $t, \rho$ gives the value of the dependent variable when explanatory variables are zero, $I N S T_{i, t}$ denotes indices of institutions and governance of country $i$ over period $t, X_{j_{i, t}}$ defines the other regressors included in the model as control variables for country $i$ over period $t, j$ is the numbers of included control variables, $\gamma_{i}$ is country-specific effect, $\in_{i}$ is the time fixed effect, and $\rho, \omega, \delta_{j}$, and $\theta$ are the parameter estimates measuring the impact of regressors on the response variable.

A country-specific fixed effect is assumed for the disturbance term as follows:

$\varepsilon_{i t}=e_{i}+\mu_{i t}$

where $\varepsilon_{i t}$ represents error term. It entails $e_{i}$, which represents country-specific fixed effects that are time invariant; meanwhile, $\mu_{i t}$ is assumed to be independent and normally distributed with zero $(0)$ mean and constant variance $\sigma_{\mu}^{2}$ both over time and across countries, that is, $u_{i t} \approx n\left(0, \sigma_{\mu}^{2}\right)$.

To adjust for the violation of the orthogonal assumption in the dynamic model in (1), we differenced the equations as follows:

$\Delta \ln N R D_{i t}=\rho+\omega \Delta \ln N R D_{i t-1}+\theta \Delta \ln I N S T_{i t}+\sum_{j=1}^{\mathrm{k}} \delta_{j} \Delta \ln X_{j_{i t}}+\Delta \mu_{i t}$

However, estimating the ordinary least square on the firstdifferenced dynamic panel model still violates the strict exogeneity assumption since the transformed error term $\Delta \mu_{i t}$ still correlates with $N R D_{i t-1}$ since both contain $\mu_{i t-1}$. The possibility of the $E\left(N R D_{i t-h} \Delta \mu_{i t}\right)=0 \forall h \geq 2, t=3, \ldots \ldots T$ makes it possible to use the lagged variable as instruments to adjust the explanatory variables to be orthogonally consistent as in Anderson and Hsiao (1982), Blundell and Bond (2000), and Blundell et al. (2001).

Our identification and exclusion restriction strategy for a non-spurious and policy consistent environmental sustainability response to institutional factors follows those employed in comprehensive GMM-centric literature. Building on Asongu et al. (2017), this study defined the regressors as endogenous with time-varying and cross-sectional factors to be strictly exogenous. This is because of the structural properties of time-invariant regressors that may prevent their convergence to endogenous component even after the initial iterative process. We referred to the Hansen test to establish instrument exogeneity. Environmental sustainability is a product of many interactive factors, as such becomes susceptible to endogeneity. Thus, there is a need for empirical clarity on exclusion restrictions that are consistent with the identification process that is favoured. We test the hypothesis of nullity using the Hansen test to establish a clear line of thought in the exclusion hypothesis.

\section{Data sources and measurements}

Our study used panel data for 53 African countries from 1996 through 2018. The choice of countries is guided by the desire to limit attention to environmental sustainability management in Africa and by the availability of reliable data on aggregates of indices of institutions and ecological degradation in Africa. All African countries have shown to have one or more dire ecological needs (Amigun et al. 2011). Structural component characteristics of variables across Africa are assumed to exhibit substantial homogeneity (Bell and Jones 2015; Honaker et al. 2011). Data for this study were sourced from World Development Indicators (WDI) and the World Governance Indicators (WGI) of the World Bank Data Base of various years up to 2018.

Environmental sustainability $E N V S U S_{i t}$ was measured using depth of natural resource depletion $N R D$ in Africa for the period under observation as in Van Der Ploeg and Poelhekke (2017). The six (6) governance and institution indices from the WGI have three (3) broad compositions: economic governance (regulation quality and government effectiveness); institutional governance (the rule of law and control of corruption); and political governance (voice \& accountability and political stability/no violence). To marginally reduce endogeneity of regressors, we relied on one randomly selected institutional/governance measure selected from each broad composition except the economic governance measures where both indices were considered because of their high precision in explaining ecological ordinances favoured by successive national governments of the selected African nations. For our broad categorisation of institutional measures, we relied on the regulatory quality and the rule of law as the economic governance measure, the rule of law as the institutional governance measure, and political stability/no violence as the political governance measures. The rule of law assesses resident assurance in prevailing judicial confinement, the strength of law enforcement strategies, and the norms of the society. The regulatory quality $R E G_{Q U A L I T Y}$ quantify government capacity to formulate and implement sound macroeconomic policy aiding private sector development. Government effectiveness $G O V T_{E F F}$ measures the strength of public services, particularly the degree to which they act independence from political interference. Political instability and the absence of violence gauge the depth of sponsored or unsolicited violence or terrorism. These measures of institutional quality agree with 
institution-centric literature (see Asongu and Nwachukwu 2016a, b; Asongu et al. 2018b; Bankole et al. 2015; Barasa et al. 2017 for some examples).

We introduced relevant control variables to avert problems of omitted variable biases and because of their high relevance in explaining changes in environmental sustainability in Africa. The control variable choice is the trade (measured as trade openness as in Nasir et al. 2020) and renewable energy options (measured as renewable energy consumption as in Nathaniel and Iheonu 2019). The intuition is that trade interactions lead to greater regional and international cooperation in the global system. Since humans (institutions) are at the core of renewable energy transformation, trade interactions where renewable energy options (solar, wind, geothermal) are consciously traded for non-renewable energy alternatives could abate growing consequences of non-renewable energy usage leading to environmental sustainability. Since governments are at the helm of affairs, they can pass laws to protect public health and create regulations to enforce trade barriers or liberalisation that encourages the substitution of renewable energy for non-renewable energy options. The variables of the study and their respective descriptions and sources are contained in Table 1.

\section{Empirical strategy}

The study made use of a four (4)-prong econometric procedure to arrive at the findings. First, the pre-estimation tests (descriptive statistics, collinearity statistics using the variance inflation factors) to ascertain the normality condition of the variables, as well as the correlation among relevant variables to produce reliable estimates (Drukker 2003) Secondly, the panel unit root testing to ensure the variables under investigation are covariance stationary. The tools used here for detecting non-stationarity of the data are the panel unit root tests developed by Levin et al. (2002), Im et al. (2003), and the Hadri LM test developed by Hadri (2000). The more traditional unit-root tests, such as the Dickey-Fuller, augmented Dickey-Fuller (ADF), Phillips-Peron, and KPSS tests, may also be applied to serve the same purpose. However, those univariate/single-equation methods are well known for their low power in small samples. By contrast, the panel unit root tests can be more potent than the conventional tests since they combine the information from the time series dimension with that from the cross-sectional dimension (Hsiao 2007).

Since the work of Levin et al. (2002), several panel unit root tests have been developed. Hence, this study used the tests developed by Levin et al. (2002), Im et al. (2003), and the Hadri LM test developed by Hadri (2000). In line with the literature, the tests are based on estimating the following model:

$$
\begin{aligned}
& \Delta Y_{i t}=\alpha_{i}+\eta_{i} y_{i t-1}+\delta_{i t}+\sum_{k=1}^{k_{i}} \theta_{i}^{(k)} \Delta y_{i t-k}+\varepsilon_{i t} \\
& \varepsilon_{i t} \sim \operatorname{iid} N\left(0, \theta_{\varepsilon}^{2}\right) i=1,2, \ldots \ldots . N, t=1,2 \ldots \ldots T
\end{aligned}
$$

where $y_{i t}$ denotes the $y$ variable observed for the $i$ th of $N$ entities in the $t$ th of $T$ periods, and $\Delta$ is the difference operator. The LLC test involves the null hypothesis $H_{0}: \rho_{i}=0 \forall i$ against the alternative $H_{A}: \rho_{i}=\rho<0 \forall i$. The IPS test involves the same null hypothesis as the LLC test, but its alternative hypothesis allows for non-stationarity for some individuals. The idea of IPS is to compute the average of the individual ADF test statistics. However, for robustness and heteroskedasticity consistency, this study also applies Hadri (2000) reconfirmation test for stationarity due to its richness in panel data stationarity confirmation. Hadri panel unit root test is similar to the KPSS unitroot test and has a null hypothesis of no unit root in any of the series in the panel. Like the Kwiatkowski et al. (1992) (KPSS) test, the Hadri test is based on the residuals from the individual OLS regressions of a constant, or on a constant and a trend. The Hadri panel unit root test requires only the specification of the form of the OLS regressions: whether to include only individual-specific constant terms, or whether to include both constant and trend terms. Stata reports two $Z$-statistic values, one based on Lagrange multiplier $\left(L M_{1}\right)$ with the associated homoskedasticity assumption and the other using $\left(L M_{2}\right)$ that is heteroskedasticity consistent. In particular, the Hadri test appears to overreject the null of stationarity and may yield results that

\begin{tabular}{|c|c|c|c|}
\hline Abbreviation & Description & Source & Motivating study \\
\hline$N R D$ & Natural Resource depletion & World Development Indicator (WDI) & Nathaniel and Iheonu 2019 \\
\hline$R U L E_{L A W_{-}}$ & Prevalence of laws & World Governance Indicator (WGI) & Kaufmann et al. 2011 \\
\hline$R E G_{Q U A L I T Y}$ & Enforcement strategies & World Governance Indicator (WGI) & Adekunle et al. 2020 \\
\hline$G O V_{E F F}$ & Effectiveness of governance & World Governance Indicator (WGI) & Iheonu 2019 \\
\hline$P O L_{I N T S}$ & Political instability/no violence & World Governance Indicator (WGI) & Ajide and Raheem 2016 \\
\hline$T R A D E$ & Trade openness & World Development Indicator (WDI) & Onanuga et al. 2020 \\
\hline$R E N E W$ & Renewable energy consumption & World Development Indicator (WDI) & Nathaniel and Iheonu 2019 \\
\hline
\end{tabular}

Table 1 Variable description 
directly contradict those obtained using alternative test statistics (see Hlouskova and Wagner 2006 for discussion and details).

After the panel unit root tests, we proceed to estimate the model using a dynamic system generalised method of moment (system GMM) as in Roodman (2009). This is because the number of the cross-section is higher than the number of time series (i.e. $N(53)>T(23)$ for this study), the essential criterion for the employment of dynamic system GMM is met. Also, the estimation approach controls for endogeneity in all regressors and cross-country differences are not eliminated in the estimation strategy. It should be noted that small sampleoriented biases that are characteristic of the difference estimator are accounted for in the system GMM strategy (Roodman 2009; Tchamyou and Asongu 2017)

\section{Results and discussion}

Table 2 shows the mean and median values of the variables in the panel dataset lie within the maximum and minimum values indicating a high tendency of the normal distribution. All the variables are positively skewed. The kurtosis statistics showed that all the variables were platykurtic, suggesting that their distributions were flat relative to a normal distribution (values are less than 3 ). The Jarque-Bera statistics shows that the series is normally distributed since the $P$ values of all the series are not statistically significant at $5 \%$ level, thus informing the acceptance of the alternate hypothesis that says each variable is normally distributed.

Results presented in Table 3 indicate that there is no existence of multicollinearity amidst the explanatory variables since the tolerance values are not less than 0.2 , and VIF values are far less than 5 . This, therefore, implies that the variables mentioned above are independent of each other and hence can be considered as independent variables assumed to affect environmental quality in Africa.
Table 3 Variance inflation factor

\begin{tabular}{|c|c|c|}
\hline \multirow[t]{2}{*}{ Variable description } & \multicolumn{2}{|c|}{ Collinearity statistics } \\
\hline & Tolerance & VIF \\
\hline $\begin{array}{l}\text { Prevalence of laws } \\
\boldsymbol{R} \boldsymbol{U} \boldsymbol{L} \boldsymbol{E}_{\boldsymbol{L} \boldsymbol{A} \boldsymbol{W}}\end{array}$ & 0.224 & 1.153 \\
\hline Enforcement strategies & 0.685 & 3.564 \\
\hline $\begin{array}{l}\boldsymbol{R E} \boldsymbol{G}_{\boldsymbol{Q U A L I T Y}} \\
\text { Effectiveness of governance } \\
\boldsymbol{G O} \boldsymbol{V}_{\boldsymbol{E F F}}\end{array}$ & 0.308 & 2.333 \\
\hline $\begin{array}{l}\text { Political Instability/no violence } \\
\boldsymbol{P O L}_{\boldsymbol{I N T S}}\end{array}$ & 0.324 & 3.626 \\
\hline $\begin{array}{l}\text { Trade openness } \\
\text { TRADE }\end{array}$ & 0.442 & 2.482 \\
\hline $\begin{array}{l}\text { Renewable Energy consumption } \\
\boldsymbol{R E N E \boldsymbol { W }}\end{array}$ & 0.253 & 2.653 \\
\hline
\end{tabular}

Source: Author's Computations. Dependent variable is the depth of natural resource depletion. Decision rule: tolerance values $\geq 0.2$ and VIF values $\leq 5$

\section{Test of slope homogeneity and cross-sectional dependence}

Specifically, cross-sectional dependence is a critical topic in panel data econometrics and ignoring cross-sectional dependence would likely create inconsistent estimates and lead to misleading information (Grossman and Krueger 1995). Also, the standard procedure, allowing only for specific heterogeneous intercepts, and not for heterogeneous slope parameters, will result in misleading estimates if the panel is heterogeneous (Breitung 2005). Considering the cross-sectional dependence and slope homogeneity that may exist within the panel data, the test for the existence of heterogeneity was carried out using the adjusted delta tilde test developed by Pesaran and Yamagata (2008) and the cross-sectional dependence test was carried using the Pesaran cross-sectional dependence (CD) test of Pesaran (2007).

Table 2 Summary statistics

\begin{tabular}{|c|c|c|c|c|c|c|c|}
\hline & $N R D$ & $R U L E_{L A W}$ & $R E G_{Q U A L I T Y}$ & $G O V_{E F F}$ & $P O L_{I N T S}$ & $T R A D E$ & RENEW \\
\hline Mean & 4.564 & 2.623 & 2.143 & 3.544 & 1.563 & 2.662 & 2.425 \\
\hline Median & 3.411 & 2.904 & 1.492 & 2.433 & 1.664 & 1.763 & 1.622 \\
\hline Maximum & 5.735 & 3.992 & 8.813 & 4.453 & 2.673 & 3.882 & 3.892 \\
\hline Minimum & -0.617 & 1.622 & 1.163 & 1.233 & 1.273 & 1.183 & 1.272 \\
\hline Std. Dev. & 3.422 & 2.222 & 1.882 & 2.454 & 0.663 & 1.767 & 1.662 \\
\hline Skewness & 3.370 & 0.522 & 2.334 & 1.482 & 2.992 & 1.626 & 2.332 \\
\hline Kurtosis & 1.642 & 2.114 & 2.232 & 1.744 & 2.773 & 2.772 & 1.883 \\
\hline Jarque-Bera & 1.010 & 1.457 & 7.723 & 2.345 & 2.774 & 2.562 & 1.562 \\
\hline Probability & 0.281 & 0.149 & 0.436 & 0.314 & 0.723 & 0.672 & 0.562 \\
\hline
\end{tabular}

Source: Author's Computations. The summary statistics were computed before taking the natural logs 
Table 4 Pesaran-Yamagata's homogeneity test

\begin{tabular}{llc}
\hline Test & Statistics & $P$ value \\
\hline $\bar{\Delta}$ & $67.32 *$ & 0.001 \\
$\mathbf{a d j} \bar{\Delta}$ & $21.43 *$ & 0.003 \\
\hline
\end{tabular}

Source: Author's Computations

$* P<0.01, * * P<0.05$ respectively

Table 4 outlines the findings based on the homogeneity test, using the calculated values of the delta tilde $(\bar{\Delta})$ and adjusted delta tilde $(\operatorname{adj} \bar{\Delta})$ and their respective $P$ values. This study confidently rejects the null hypothesis of the slope coefficients being homogeneous at a level of significance of $1 \%$. This, therefore, implies that heterogeneity exists for all the analysed variables in the various country groups. Thus, heterogeneous panel methods in which parameters differ across individual cross-sections within the panels were adopted.

In addition to the homogeneity test, Table 5 reports on findings from the $\mathrm{CD}$ test. By referring to the $\mathrm{CD}$ test values and their corresponding probability values, it can be verified that the probability values for the various $C D$ test values of all variables within the panel are significant at $1 \%$ level leading to the rejection of the null hypothesis of cross-sectional independence. This, therefore, gives the implication that there is sufficient cross-sectional dependency among variables across all countries in different panels. From a policy perspective, it is crucial to consider this heterogeneity and cross-sectional correlation when formulating environmental sustainability policies in Africa to account for potential influences arising from institutional differences. Strong evidence of heterogeneity and cross-sectional dependence among groups of African economies for several variables requires the importance of applying second-generation panel unit root test that accounts for crosssectional dependence. Phillips and Sul (2003) indicate that the efficiency of estimation results in many substantially decrease, given that cross-sectional correlations and heterogeneity exist across countries within a panel data and this is overlooked in estimation as many researchers commonly do it. Hence, the Im, Pesaran, and Chin test (first-generation), Levin, Lin, and Chin test, and the Hadri LM test (second-generation test) are implemented in the study. Given the observation of heterogeneity and cross-sectional dependence, panel data methods adopted in this study consider problems of heterogeneity and cross-sectional dependence to provide reliable and accurate results.

\section{Panel unit root}

The outcomes of Levin et al. (2002); Im et al. (2003); and the Hadri (2000) panel unit root tests are shown in Table 6.

All tests confirmed that variables are non-stationary at levels but are stationary at first difference. It is as a result of this inferred that variables are first-differenced stationary. These empirical outcomes did uncover not only the nonstationary properties of all the variables but also established the covariance nature of the data set under investigation. We proceed to estimate the two-step dynamic system generalised method of moment (GMM). This is indispensable in this research because the choice of the estimation strategy is consistent with the data behaviour and in consonance with contemporary GMM-centric literature (see Asongu and Nwachukwu 2016c; Roodman 2009 for some examples).

From Table 7, the coefficient of the lagged dependent variable is positive and statistically significant at $5 \%$ level. This conforms with the rent-seeking theory, which states that more and more of state resources used will trigger even more use of existing resources. Thus, a percentage increase lagged dependent variable will result in a $0.04 \%$ increase in natural resource depletion in Africa. Hence, the decline in the pursuit of environmental sustainability pattern in Africa is motivated by rent seekers dominating various African geographies and spaces.

Also, the coefficient of the indices of the institution and governance shows (the rule of law, regulatory quality) exhibits a negative relationship with natural resource depletion, thereby causing the transformation to environmental sustainability in Africa. A percentage increase in the rule of law will result in 0.059 percentage decrease in natural resource depletion in Africa while a percentage increase in regulatory quality will result in 0.567 percentage decrease in natural resource depletion. That is, strong institutions and right governance aid transformation to environmental sustainability. However, government effectiveness and political instability/absence of violence exhibit a positive relationship with environmental sustainability. A percentage increase in government

Table 5 Pesaran cross-sectional dependence test

\begin{tabular}{|c|c|c|c|c|c|c|c|}
\hline & $N R D$ & $R U L E \_L A W$ & $R E G_{-} Q A L I T Y$ & $G O V_{-} E F F$ & $P O L_{I N T S}$ & TRADE & RENEW \\
\hline $\mathrm{CD}$ test value & $12.65^{*}$ & $21.47 *$ & $31.34 *$ & $11.45^{*}$ & $43.11 *$ & $21.65^{*}$ & $11.44 *$ \\
\hline Prob. & 0.00 & 0.00 & 0.00 & 0.00 & 0.00 & 0.00 & 0.00 \\
\hline
\end{tabular}

Source: Author's Computations

$* P<0.01, * * P<0.05$ respectively 


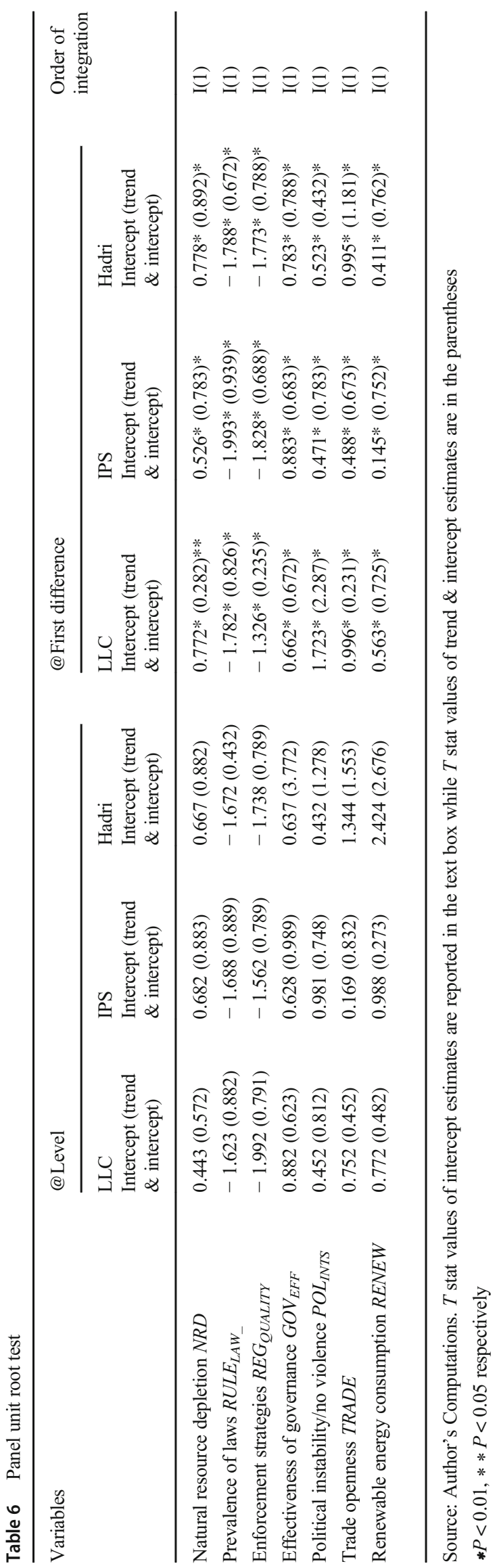

effectiveness and political instability/lack of violence will result in a percentage increase in natural resource depletion, causing more significant and marked environmental degradation in Africa by $0.803 \%$ and $0.405 \%$. In other climes of the obtained results, trade openness is negatively and statistically significant at 5\%; thus, a percentage increase in exposure to trade will result into $0.815 \%$ increase in natural resource depletion leading to shallow environmental sustainability pursuits. Renewable energy consumption is negative and statistically significant at 5\% and by implication leads to $0.429 \%$ decrease in natural resource depletion in Africa.

I proceeded to establish the validity of the instrument used in the system GMM technique. Compared to the OLS model system, GMM does not assume normality, and it allows for heteroscedasticity in the data. Dynamic panels irrespective of the kind of model are known for the problems of heteroskedasticity in the data set, which can be controlled (Onanuga et al. 2020). The system GMM approach assumes linearity and that the error terms not autocorrelated justifying the need to test for the validity of the instruments through the examination of the first-order and second-order autocorrelation in the disturbance term. In tandem with Arellano and Bond (1991), the GMM estimator requires the presence of first-order serial correlation and not the second-order serial correlation in the residual term. Since the null hypothesis inference assumes no first-order and second-order serial correlation, we reject the null hypothesis in the first-order serial correlation and accept the null hypothesis for second-order serial correlation test in order to obtain appropriate diagnostics. The result above confirms the existence of first-order serial correlation since the null hypothesis of first-order serial correlation was rejected $(z=-2.54 ; P<0.05)$ at $5 \%$ significance level and no second-order serial correlation since null hypothesis of no second-order serial correlation is accepted because calculated $z$ is not statistically significant at $5 \%$ $(z=-0.84 ; P>0.05)$, thus supporting the validity of our model specification.

The Hansen $J$ statistics test the null hypothesis of correct specification and valid over-identified restrictions, i.e. the validity of instruments (Oguzie et al. 2005). They argued further that Hansen $J$ statistics is the most commonly used diagnostic test in GMM estimation for assessment of the appropriateness of the model. The results of the Hansen $J$ statistics of overidentifying restrictions do not reject the null hypothesis at any conventional level of significance $(P>0.05$; i. e. $P=0.851)$, thus confirming the model has valid instrumentation. The $F$ statistics value of all the variables are jointly significant at $5 \%$ level of significance.

\section{Robustness results}

In order to check the validity of the system GMM results, the study also employed pooled OLS and fixed effects in 


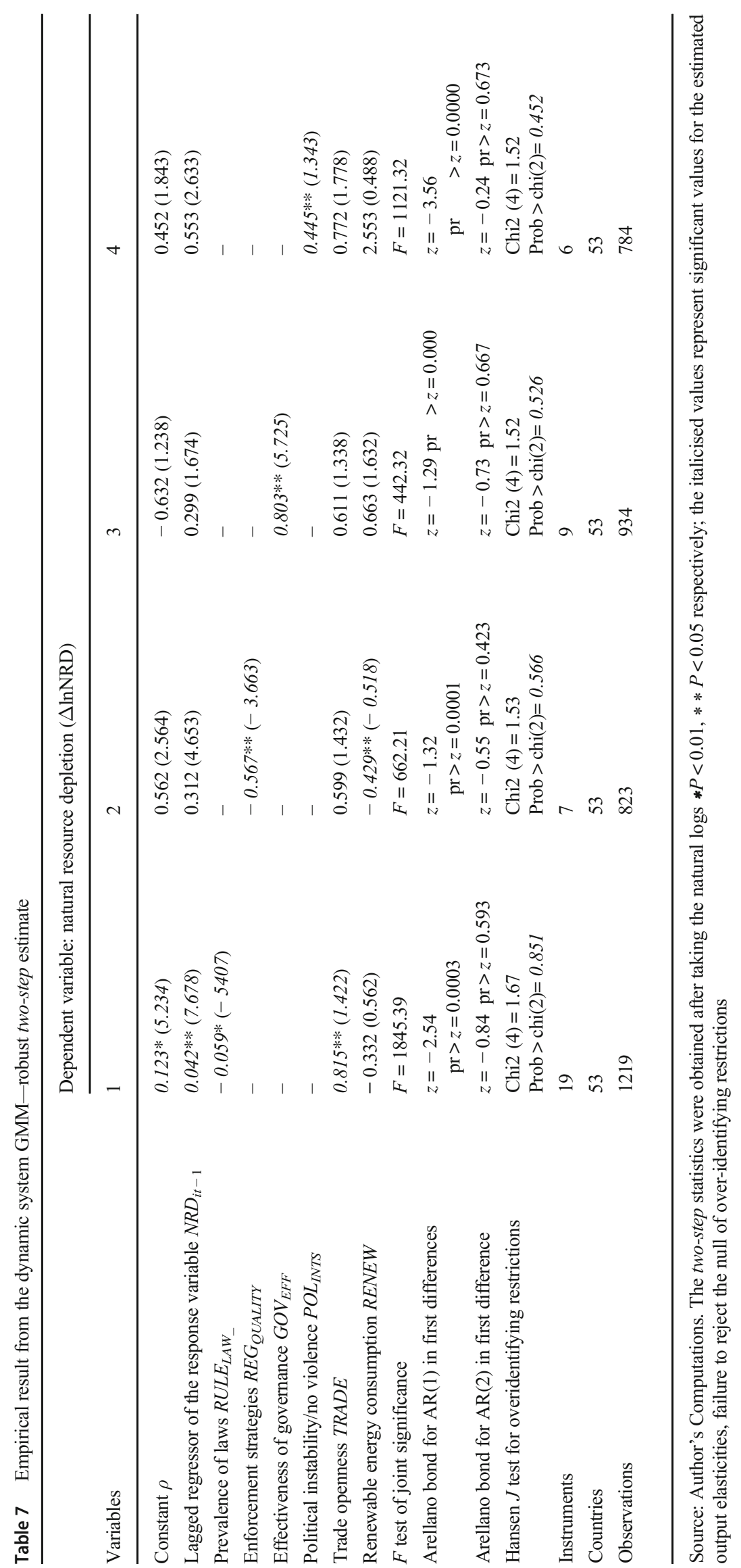


Table 8 Pooled ordinary least square results

\begin{tabular}{|c|c|c|c|c|}
\hline \multirow[b]{2}{*}{ Variables } & \multicolumn{4}{|c|}{ Dependent variable: natural resource depletion $(\Delta \operatorname{lnNRD})$} \\
\hline & 1 & 2 & 3 & 4 \\
\hline Constant $\rho$ & $0.452 *(3.764)$ & $0.823(1.631)$ & $-1.432(1.331)$ & $1.332(0.231)$ \\
\hline Lagged regressor of the response variable $N R D_{i t-1}$ & $0.167 * *(3.452)$ & $1.432(2.672)$ & $0.482(0.432)$ & $0.982(1.873)$ \\
\hline Prevalence of laws $R U L E_{L A W_{-}}$ & $-0.059 *(2.562)$ & - & - & - \\
\hline Enforcement strategies $R E G_{Q U A L I T Y}$ & - & $0.503 *(6.472)$ & - & - \\
\hline Effectiveness of governance $G O V_{E F F}$ & - & - & $-0.601 * *(-3.546)$ & - \\
\hline Political instability/no violence $P O L_{I N T S}$ & - & - & - & $-0.562 * *(-1.452)$ \\
\hline Trade openness $T R A D E$ & $-0.328 * *(1.329)$ & $0.321(4.442)$ & $2.234(3.443)$ & $2.432(1.434)$ \\
\hline Renewable energy consumption $R E N E W$ & $-0.771(0.533)$ & $-0.344 * *(-2.482)$ & $0.443(1.443)$ & $2.778(0.344)$ \\
\hline$F$ stat & $75.772 *$ & $231.432 *$ & $49.325^{*}$ & $98.527 *$ \\
\hline Adjusted $R^{2}$ & 0.624 & 0.782 & 0.562 & 0.832 \\
\hline Countries & 53 & 53 & 53 & 53 \\
\hline Observations & 1219 & 823 & 934 & 784 \\
\hline
\end{tabular}

Source: Author's Computations. The statistics were obtained after taking the natural $\operatorname{logs} * P<0.01, * * P<0.05$, respectively; the italicised values represent significant values for the estimated output elasticities

consonance with Blundell et al. (2001). They suggested additional detections of dynamic panel validity by checking if the estimated coefficient of the lagged dependent variables lies between the values obtained from pooled ordinary least square (POLS) and fixed effect (FE) estimator. Our results established that in Tables 8 and 9, the coefficient of the lagged dependent variables of the system GMM results lies between the values obtained from POLS and FE estimators $(F E=-0.137<G M M=0.042<P O L S=0.167)$

\section{Conclusions, policy relevance, and suggestions for further studies}

Despite extensive and active discussions on environmental sustainability, empirical credence illuminating on how African indigenous and institutional capacities modulate environmental sustainability pursuit management remains dimly discerned. This observed gap in the literature of ecological sustainability clouds our understanding on the magnitude of

Table 9 Fixed effect results

\begin{tabular}{|c|c|c|c|c|}
\hline \multirow[b]{2}{*}{ Variables } & \multicolumn{4}{|c|}{ Dependent variable: natural resource depletion $(\Delta \operatorname{lnNRD})$} \\
\hline & 1 & 2 & 3 & 4 \\
\hline Constant $\rho$ & $0.543^{*}(1.234)$ & $0.572(1.882)$ & $-1.232(0.832)$ & $1.435(2.323)$ \\
\hline Lagged regressor of the response variable $N R D_{i t-1}$ & $0.137 * *(4.562)$ & $0.662(1.322)$ & $1.233(1.663)$ & $0.222(1.662)$ \\
\hline Prevalence of laws $R U L E_{L A W_{-}}$ & $0.932 *(3.489)$ & - & - & - \\
\hline Enforcement strategies $R E G_{Q U A L I T Y}$ & - & $0.567 * *(1.978)$ & - & - \\
\hline Effectiveness of governance $G O V_{E F F}$ & - & - & $-0.618 * *(-4.343)$ & - \\
\hline Political instability/no violence $P O L_{I N T S}$ & - & - & - & $-0.455^{* *}(-1.462)$ \\
\hline Trade openness TRADE & $-0.614 * *(1.692)$ & $1.377(1.432)$ & $0.822(1.345)$ & $0.421(1.623)$ \\
\hline Renewable energy consumption $R E N E W$ & $-0.332(0.562)$ & $-0.721 * *(-1.662)$ & $0.663(1.221)$ & $1.672(0.628)$ \\
\hline$F$ stat & $71.662 *$ & $73.323^{*}$ & $23.985^{*}$ & $113.322 *$ \\
\hline Adjusted $R^{2}$ & 0.672 & 0.233 & 0.332 & 0.772 \\
\hline Countries & 53 & 53 & 53 & 53 \\
\hline Observations & 1219 & 823 & 934 & 784 \\
\hline
\end{tabular}

Source: Author's Computations. The statistics were obtained after taking the natural logs $* P<0.01, * * P<0.05$ respectively; the italicised values represent significant values for the estimated output elasticities 
influence institutional factors can have ensuring the environment is preserved in a manner that equilibrates the welfare gains of imminent and contemporaneous generations. For these reasons, this paper explains the roles of institutions and governance in the attainment of environmental sustainability in Africa from 1996 through 2018. In evaluating its objectives, the paper adopts the dynamic system GMM to account for the short-run dynamics of the model as well as established the robustness of the model estimated. The empirical result reveals that the indices of institution and governance (the rule of law, regulatory quality) exhibit a positive relationship with the transformation to environmental sustainability in Africa while government effectiveness exhibit an inverse relationship with environmental sustainability. From the result, it is evident that strong institutions, particularly in terms of their capacity to deliver the dividends of democracy and regional monarchical rules to the good people of Africa, are the only way to ensure the transformation to environmental sustainability through various green policy formulation and implementation. The findings of this study align with the results of Cobbinah et al. (2015), Ding et al. (2016), Hewitt (2013), and Salisu Barau et al. (2016). It is therefore recommended that governments and institutions should form the starting point of the transformation to environmental sustainability pursuit with particular reference given to the greenhouse policy formulation and implementation strategies.

In place of the limitations of this study which consider panel data across the continent, regional studies on the institution-environmental degradation will be more insightful since laws and enforcement strategies are heterogeneous across geography and space. An enquiry into the regional implications of institution-environmental sustainability relations will most likely produce a result that is most inclined to the local or country development objectives.

Author contributions I.A. as the sole author came up with the entirety of the manuscript.

Data availability The dataset(s) supporting the conclusions of this article is available in the World Bank Database of various issues up to 2018 (World Bank 2018) (https://data.worldbank.org/) and World Governance Indicators (WGI) (https://info.worldbank.org/governance/wgi/).

\section{Compliance with ethical standards}

Ethical approval N/A

Consent to participate N/A

Consent to publish N/A

Competing interests The author declares that he has no competing interests.

\section{References}

Adekunle IA, Williams TO, Omokanmi OJ, Onayemi SO (2020) Mediating roles of institutions in the remittance-growth relationship: evidence from Nigeria. Forthcoming in Economic Annals. Available at https://ideas.repec.org/p/exs/wpaper/20-063.html

Ahenkan A, Osei-Kojo A (2014) Achieving sustainable development in Africa: progress, challenges and prospects. Int J Dev Sustain 3(1): $162-176$

Ajide KB, Raheem ID (2016) Institutions-FDI nexus in ECOWAS countries. J Afr Bus 17(3):319-341. https://doi.org/10.1080/15228916. 2016.1180778

Amigun B, Musango JK, Stafford W (2011) Biofuels and sustainability in Africa. Renew Sust Energ Rev 15(2):1360-1372. https://doi.org/10. 1016/j.rser.2010.10.015

Anderson TW, Hsiao C (1982) Formulation and estimation of dynamic models using panel data. J Econ 18(1):47-82. https://doi.org/10. 1016/0304-4076(82)90095-1

Arellano M, Bond S (1991) Some tests of specification for panel data: Monte Carlo evidence and an application to employment equations. Rev Econ Stud 58(2):277-297. https://doi.org/10.2307/2297968

Arellano M, Bover O (1995) Another look at the instrumental variable estimation of error-components models. J Econom 68(1):29-51. https://doi.org/10.1016/0304-4076(94)01642-D

Asongu SA, Acha-Anyi PN (2019) The murder epidemic: a global comparative study. Int Crim Justice Rev 29(2):105-120

Asongu SA, Nwachukwu JC (2016a) Foreign aid and governance in Africa. Int Rev Appl Econ 30(1):69-88. https://doi.org/10.1080/ 02692171.2015.1074164

Asongu SA, Nwachukwu JC (2016b) The mobile phone in the diffusion of knowledge for institutional quality in sub-Saharan Africa. World Dev 86:133-147. https://doi.org/10.1016/j.worlddev.2016.05.012

Asongu SA, Nwachukwu JC (2016c) The role of governance in mobile phones for inclusive human development in sub-Saharan Africa. Technovation 55-56:1-13. https://doi.org/10.1016/j.technovation. 2016.04.002

Asongu SA, Odhiambo NM (2020) Enhancing governance for environmental sustainability in sub-Saharan Africa. Energy Exploration \& Exploitation. Available at https://doi.org/10.1177/ 0144598719900657

Asongu SA, Le Roux S, Biekpe N (2017) Environmental degradation, ICT and inclusive development in sub-Saharan Africa. Energy Policy 111:353-361. https://doi.org/10.1016/j.enpol.2017.09.049

Asongu SA, Le Roux S, Biekpe N (2018a) Enhancing ICT for environmental sustainability in sub-Saharan Africa. Technol Forecast Soc Chang 127:209-216. https://doi.org/10.1016/j.techfore.2017.09. 022

Asongu SA, Nwachukwu JC, Orim SMI (2018b) Mobile phones, institutional quality and entrepreneurship in sub-Saharan Africa. Technol Forecast Soc Chang 131:183-203. https://doi.org/10. 1016/j.techfore.2017.08.007

Balmford A, Moore JL, Brooks T, Burgess N, Hansen LA, Williams P, Rahbek C (2001) Conservation conflicts across Africa. Science 291(5513):2616-2619. https://doi.org/10.1126/science.291.5513. 2616

Bankole FO, Osei-Bryson KM, Brown I (2015) The impacts of telecommunications infrastructure and institutional quality on trade efficiency in Africa. Inf Technol Dev 21(1):29-43. https://doi.org/10.1080/ 02681102.2013 .874324

Barasa L, Knoben J, Vermeulen P, Kimuyu P, Kinyanjui B (2017) Institutions, resources and innovation in East Africa: a firm level approach. Res Policy 46(1):280-291. https://doi.org/10.1016/j. respol.2016.11.008 
Bell A, Jones K (2015) Explaining fixed effects: random effects modeling of time-series cross-sectional and panel data. Polit Sci Res Methods 3(1):133-153. https://doi.org/10.1017/psrm.2014.7

Ben Youssef A, Boubaker S, Omri A (2018) Entrepreneurship and sustainability: the need for innovative and institutional solutions. Technol Forecast Soc Chang 129:232-241. https://doi.org/10. 1016/j.techfore.2017.11.003

Berman R, Quinn C, Paavola J (2012) The role of institutions in the transformation of coping capacity to sustainable adaptive capacity. Environ Dev 2:86-100. https://doi.org/10.1016/j.envdev.2012.03. 017

Bhattarai M, Hammig M (2001) Institutions and the environmental Kuznets curve for deforestation: a crosscountry analysis for Latin America, Africa and Asia. World Dev 29(6):995-1010. https://doi. org/10.1016/S0305-750X(01)00019-5

Blundell R, Bond S (2000) GMM estimation with persistent panel data: an application to production functions. Econ Rev 19(3):321-340. https://doi.org/10.1080/07474930008800475

Blundell R, Bond S, Windmeijer F (2001) Estimation in dynamic panel data models: improving on the performance of the standard GMM estimator. Adv Econ 15:53-91. https://doi.org/10.1016/S07319053(00)15003-0

Bokpin GA (2017) Foreign direct investment and environmental sustainability in Africa: the role of institutions and governance. Res Int Bus Financ 39:239-247. https://doi.org/10.1016/j.ribaf.2016.07.038

Bradlow B, Bolnick J, Shearing C (2011) Housing, institutions, money: the failures and promise of human settlements policy and practice in South Africa. Environ Urban 23(1):267-275. https://doi.org/10. $1177 / 0956247810392272$

Breitung J, Das S (2005) Panel unit root tests under cross-sectional dependence. Stat Neerl 59(4):414-433. https://doi.org/10.1111/j. 1467-9574.2005.00299.x

Cobbinah PB, Erdiaw-Kwasie MO, Amoateng P (2015) Africa's urbanisation: implications for sustainable development. Cities 47:62-72. https://doi.org/10.1016/j.cities.2015.03.013

Deep S, Saklani A (2014) Urban sprawl modeling using cellular automata. Egypt J Remote Sens Space Sci 17(2):179-187. https://doi.org/ 10.1016/j.ejrs.2014.07.001

Ding H, Liu Q, Zheng L (2016) Assessing the economic performance of an environmental sustainable supply chain in reducing environmental externalities. Eur J Oper Res 255(2):463-480. https://doi.org/10. 1016/j.ejor.2016.05.003

Drukker DM (2003) Testing for serial correlation in linear panel-data models. The Stata Journal: Promoting Communications on Statistics and Stata. https://doi.org/10.1177/1536867x0300300206

Easterly W, Levine R (1997) Africa's growth tragedy: policies and ethnic divisions. Q J Econ 112(4):1203-1250. https://doi.org/10.1162/ 003355300555466

Epstein G, Pittman J, Alexander SM, Berdej S, Dyck T, Kreitmair U, Rathwell KJ, Villamayor-Tomas S, Vogt J, Armitage D (2015) Institutional fit and the sustainability of social-ecological systems. Curr Opin Environ Sustain 14:34-40. https://doi.org/10.1016/j. cosust.2015.03.005

Foley JA, Ramankutty N, Brauman KA, Cassidy ES, Gerber JS, Johnston M, Mueller ND, O'Connell C, Ray DK, West PC, Balzer C, Bennett EM, Carpenter SR, Hill J, Monfreda C, Polasky S, Rockström J, Sheehan J, Siebert S, Tilman D, Zaks DPM (2011) Solutions for a cultivated planet. Nature 478(7369):337-342. https://doi.org/10. 1038 /nature 10452

Friedl G, Wüest A (2002) Disrupting biogeochemical cyclesconsequences of damming. Aquat Sci 64:55-65. https://doi.org/10. 1007/s00027-002-8054-0

Frumkin H (2002) Urban sprawl and public health. Public Health Rep 117(3):201-217. https://doi.org/10.1016/S0033-3549(04)50155-3

Grossman GM, Krueger AB (1995) Economic growth and the environment. Q J Econ 110(2):353-377. https://doi.org/10.2307/2118443
Gu J, Renwick N, Xue L (2018) The BRICS and Africa's search for green growth, clean energy and sustainable development. Energy Policy 120:675-683. https://doi.org/10.1016/j.enpol.2018.05.028

Hadri K (2000) Testing for stationarity in heterogeneous panel data. Econ J 3(2):148-161. https://doi.org/10.1111/1368-423x.00043

Henderson DJ, Carroll RJ, Li Q (2008) Nonparametric estimation and testing of fixed effects panel data models. J Econ 144(1):257-275. https://doi.org/10.1016/j.jeconom.2008.01.005

Hewitt K (2013) Environmental disasters in social context: toward a preventive and precautionary approach. Nat Hazards 66:3-14. https://doi.org/10.1007/s11069-012-0205-6

Hlouskova J, Wagner M (2006) The performance of panel unit root and stationarity tests: results from a large scale simulation study. Econ Rev 25(1):85-116. https://doi.org/10.1080/07474930500545504

Honaker J, King G, Blackwell M (2011) Amelia II: a program for missing data. J Stat Softw 45(7):1-47. https://doi.org/10.18637/jss.v045.i07

Hsiao C (2007) Panel data analysis-advantages and challenges. Test 16: 1-22. https://doi.org/10.1007/s11749-007-0046-x

Hsieh HF, Shannon SE (2005) Three approaches to qualitative content analysis. Qual Health Res 15(9):1277-1288. https://doi.org/10. $1177 / 1049732305276687$

Iheonu C (2019) Governance and domestic investment in Africa. Eur J Govern Econ 8(1):63-80

Im KS, Pesaran MH, Shin Y (2003) Testing for unit roots in heterogeneous panels. J Econ 115(1):53-74. https://doi.org/10.1016/S03044076(03)00092-7

Jolley D, Douglas KM (2014) The effects of anti-vaccine conspiracy theories on vaccination intentions. PLoS ONE 9(2):89177. https:// doi.org/10.1371/journal.pone.0089177

Kaufmann D, Kraay A, Mastruzzi M (2011) The worldwide governance indicators: methodology and analytical issues. Hague J Rule Law 3(2):220-246. https://doi.org/10.1017/S1876404511200046

Kumssa A, Mbeche IM (2004) The role of institutions in the development process of African countries. Int J Soc Econ 31(9):840-854. https:// doi.org/10.1108/03068290410550638

Kwiatkowski D, Phillips PCB, Schmidt P, Shin Y (1992) Testing the null hypothesis of stationarity against the alternative of a unit root. How sure are we that economic time series have a unit root? J Econ 54(13):159-178. https://doi.org/10.1016/0304-4076(92)90104-Y

Lehtonen M (2004) The environmental-social interface of sustainable development: capabilities, social capital, institutions. Ecol Econ 49(2):199-214. https://doi.org/10.1016/j.ecolecon.2004.03.019

Levin A, Lin CF, Chu CSJ (2002) Unit root tests in panel data: asymptotic and finite-sample properties. J Econ 108(1):1-24. https://doi.org/10. 1016/S0304-4076(01)00098-7

Mazzucato V, Niemeijer D (2002) Population growth and the environment in Africa: local informal institutions, the missing link. Econ Geogr 78(2):171-193. https://doi.org/10.2307/4140786

Mbhalati OJ (2014) Reinventing the public sector in Africa through knowledge management. Knowl Manag Res Pract 12(1):114-121. https://doi.org/10.1057/kmrp.2013.5

McConnell KE (1997) Income and the demand for environmental quality. Environ Dev Econ 2(4):383-399. https://doi.org/10.1017/ S1355770X9700020X

Murtazashvili I, Wooldridge JM (2008) Fixed effects instrumental variables estimation in correlated random coefficient panel data models. J Econ 142(1):539-552. https://doi.org/10.1016/j.jeconom.2007.09. 001

Nasir MA, Canh NP, Le TNL (2020) Environmental degradation \& role of financialisation, economic development, industrialisation and trade liberalisation. J Environ Manag 277:111471. https://oi.org/ 10.1016/j.jenvman.2020.111471

Nathaniel SP, Iheonu CO (2019) Carbon dioxide abatement in Africa: the role of renewable and non-renewable energy consumption. Sci Total Environ 679:337-345. https://doi.org/10.1016/j.scitotenv.2019.05. 011 
Oguzie EE, Onuoha GN, Onuchukwu AI (2005) Inhibitory mechanism of mild steel corrosion in $2 \mathrm{M}$ sulphuric acid solution by methylene blue dye. Mater Chem Phys 89(2-3):305-311. https://doi.org/10. 1016/j.matchemphys.2004.09.004

Onanuga AT, Odusanya IA, Adekunle IA (2020) Terrorism and financial flows in Africa. Behav Sci Terrorism and Polit Aggress:1-18. https://doi.org/10.1080/19434472.2020.1736128

Ostrom E (2008) Institutions and the environment. Econ Aff 28(3):24 31. https://doi.org/10.1111/j.1468-0270.2008.00840.x

Pesaran MH (2007). A simple panel unit root test in the presence of crosssection dependence. J Appl Econom 22(2):265-312. https://doi.org/ 10.1002/jae.951

Pesaran MH, Yamagata T (2008) Testing slope homogeneity in large panels. J Econom 142(1):50-93. https://doi.org/10.1016/j.jeconom. 2007.05.010

Phillips PCB, Sul D (2003) Dynamic panel estimation and homogeneity testing under cross section dependence. J Econom 6:217-259. https://doi.org/10.1111/1368-423X.00108

Prilleltensky I (2012) Wellness as fairness. Am J Community Psychol 49(1-2):1-21. https://doi.org/10.1007/s10464-011-9448-8

Roodman D (2009) How to do xtabond2: an introduction to difference and system GMM in Stata. Stata J 9(1):86-136. https://doi.org/10. 1177/1536867x0900900106

Salisu Barau A, Stringer LC, Adamu AU (2016) Environmental ethics and future oriented transformation to sustainability in sub-Saharan Africa. J Clean Prod 135(1):1539-1547. https://doi.org/10.1016/j. jclepro.2016.03.053

Shackleton CM, Shackleton SE, Buiten E, Bird N (2007) The importance of dry woodlands and forests in rural livelihoods and poverty alleviation in South Africa. Forest Policy Econ 9(5):558-577. https:// doi.org/10.1016/j.forpol.2006.03.004
Sowman M, Wynberg R (2014) Governance for justice and environmental sustainability: lessons across natural resource sectors in subSaharan Africa. https://doi.org/10.4324/9780203120880

Su L, Yang Z (2015) QML estimation of dynamic panel data models with spatial errors. J Econ 185(1):230-258. https://doi.org/10.1016/j. jeconom.2014.11.002

Tchamyou VS (2019) The role of information sharing in modulating the effect of financial access on inequality. J Afr Bus 20(3):317-338. https://doi.org/10.1080/15228916.2019.1584262

Tchamyou VS, Asongu SA (2017) Information sharing and financial sector development in Africa. J Afr Bus 18(1):24-49. https://doi. org/10.1080/15228916.2016.1216233

Turner MD (1999) Conflict, environmental change, and social institutions in dryland Africa: limitations of the community resource management approach. Soc Nat Resour 12(7):643-657. https://doi.org/ $10.1080 / 089419299279362$

Van Der Ploeg F, Poelhekke S (2017) The impact of natural resources: survey of recent quantitative evidence. J Dev Stud 53(2):205-216. https://doi.org/10.1080/00220388.2016.1160069

Walker PA (1999) Democracy and environment: congruencies and contradictions in southern Africa. Polit Geogr 18(3):257-284. https:// doi.org/10.1016/S0962-6298(98)00102-4

World Health Organization (2014) The top 10 causes of death. Available at https://www.who.int/news-room/fact-sheets/detail/the-top-10causes-of-death. Accessed 17 Feb 2020

Publisher's note Springer Nature remains neutral with regard to jurisdictional claims in published maps and institutional affiliations. 